\title{
Association of reproductive factors with the incidence of breast cancer in Gulf Cooperation Council countries
}

\author{
K. Ravichandran ${ }^{1}$ and A.S. Al-Zahrani ${ }^{1}$
}

$$
\begin{aligned}
& \text { التـر ابط بين العو امل الإنجابيّة ومعدَّل حدوث سرطان الثدي في بلدان بجلس التعاون }
\end{aligned}
$$

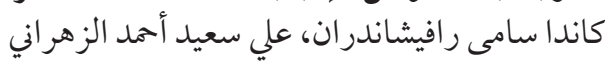

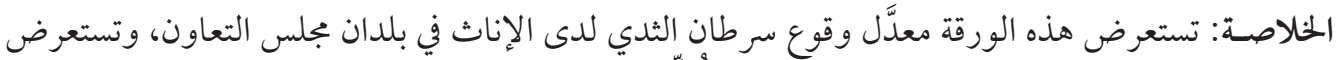

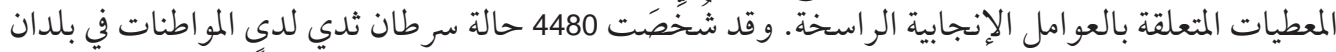

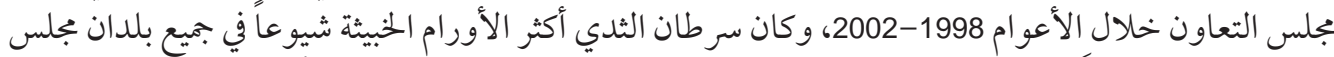

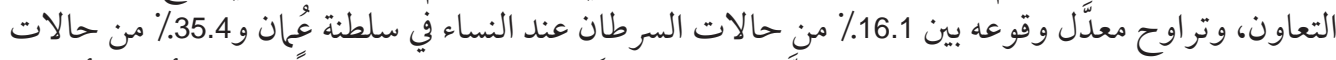

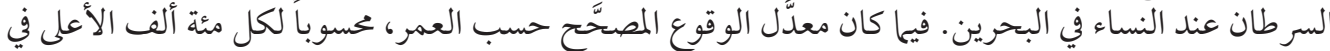

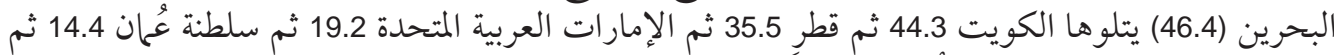

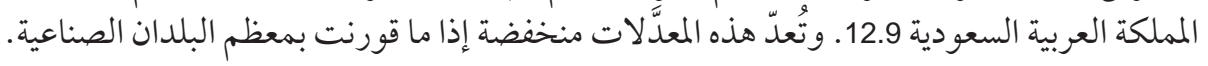

ABSTRACT This article presents the incidence of female breast cancer in the Gulf Cooperation Council (GCC) countries and reviews the data in relation to established reproductive factors. Overall 4480 female breast cancer cases were diagnosed during 1998-2002 among GCC country nationals. Breast cancer was the most common malignancy in all GCC countries, ranging from $16.1 \%$ of female cancers in Oman to 35.4\% in Bahrain. The age-standardized incidence rate per 100000 was highest in Bahrain (46.4), followed by Kuwait (44.3), Qatar (35.5), United Arab Emirates (19.2), Oman (14.4) and Saudi Arabia (12.9). These rates are low compared with most industrialized countries.

\begin{abstract}
Lien entre les facteurs liés à la reproduction et l'incidence du cancer du sein dans les pays du Conseil de coopération du Golfe

RÉSUMÉ Cet article décrit l'incidence du cancer du sein féminin dans les pays du Conseil de Coopération du Golfe (CCG) et analyse ces données par rapport aux facteurs liés à la reproduction établis. Au total, 4480 cas de cancer du sein ont été diagnostiqués de 1998 à 2002 chez des ressortissantes des pays du CCG. Le cancer du sein était l'affection maligne la plus courante dans tous ces pays, avec des taux de cancer féminin compris entre 16,1\% à Oman à 35,4\% à Bahreïn. L'incidence normalisée en fonction de l'âge pour 100000 habitants était la plus élevée à Bahreïn $(46,4)$, suivi du Koweït $(44,3)$, du Qatar $(35,5)$, des Émirats arabes unis $(19,2)$, d'Oman $(14,4)$ et de l'Arabie saoudite $(12,9)$. Ces taux sont faibles comparés à la plupart des pays industrialisés.
\end{abstract}

${ }^{1}$ Department of Biostatistics, Epidemiology and Scientific Computing, King Faisal Specialist Hospital and Research Centre, Riyadh, Saudi Arabia (Correspondence to A.S. Al-Zahrani: alisaz@kfshrc.edu.sa). Received: 14/09/06; accepted: 03/12/06 


\section{Introduction}

Breast cancer is the second most common cancer in the world today and the most frequent malignant neoplasm occurring in women. Worldwide an estimated 1151298 women were diagnosed with breast cancer by 2002 , accounting for $22.7 \%$ of all female cancers. More than half of these occurred in developed countries. The age-standardized incidence rates of breast cancer vary widely throughout the world, the highest being observed in North America. High rates are also observed in Western Europe, Australia and New Zealand. In contrast, low rates are found in most African and Asian populations, although in some Asian populations they are the same as in Southern Europe, and in some cases even higher. There is a large variation (up to 6-fold) in the incidence of breast cancer between different regions [1]. The large difference between industrialized and non-industrialized countries is remarkable. Significant variations in incidence have also been observed within more limited geographic areas [2].

Several studies have shown that breast cancer is the highest incident cancer among women in the Gulf Cooperation Council (GCC) countries [3-9]. However, these data on cancer incidence were hospital-based, and from specialized centres, reflecting referral patterns rather than true incidence.

This population-based study is the first to outline the incidence of breast cancer in GCC countries and review the incidence in relation to aspects of the reproductive history of women that have been established as risk factors for female breast cancer.

\section{Methods}

The Gulf Centre for Cancer Registration (GCCR) was established to create cancer incidence databases (including cases of benign and malignant tumours) for the GCC countries. The GCCR obtains data on cancer incidence and population from the 7 national cancer registries of the United Arab Emirates (UAE), Bahrain, Saudi Arabia, Oman, Qatar, Kuwait and Yemen. Yemen was excluded from this study due to the unavailability of data corresponding to the period of the study, 1988-2002.

The national cancer registry in each country is responsible for data collection from the health facilities of its country. Cancer is a reportable disease in all Ministry of Health hospitals, and government and private hospitals, clinics and laboratoriess. Data are collected from patients' medical records based on clinical and histological diagnosis of cancer by a registrar in addition to direct reporting of cases to the registry from hospitals/institutions. Efforts are made by each registry to ensure that each case is eligible and registered only once in the registry. The GCCR collates the cancer data collected from all the GCC countries after strict quality assurance [10].

The age-specific rate and age-standardized rate (ASR), standardized to the world standard population, were used to describe the incidence. For each country, the female population (with nationality of that country) in 5-year age categories was estimated on 1 July 2000. We attempted to evaluate the relationship between the incidence of breast cancer and known risk factors related to the reproductive history of the women, obtained from the family health survey (FHS) in all GCC countries [11-16].

\section{Results}

\section{Breast cancer incidence}

During 1998-2002, a total of 20547 cases of cancer were registered among women in the GCCR among GCC nationals; 4480 $(21.8 \%)$ of these were primary breast cancer

المجلة الصحية لشرق المتوسط، منظمة الصحة العالمية، المجلد الخنامس عشر، العدد ب، 9 +. 
(Table 1). Cancer of the breast was by far the most common major malignancy among females, ranging from $16.1 \%$ of female cancers in Oman to $35.4 \%$ in Bahrain.

The mean age at diagnosis was highest in Kuwait [50.4 [standard deviation (SD) 12.4) years], followed by Bahrain [49.0 (SD 12.5) years] (Table 1$)$.

Overall, only $39(0.9 \%)$ cases (2 UAE, 3 Bahrain, 28 Saudi Arabia and 6 Oman) occurred in women aged $<25$ years. However, $2567(57.3 \%)$ cases were in women aged 25-50 years at diagnosis. The incidence of breast cancer increased with the women's age up to 69 years, but the rate of increase slowed at around 50 years (Table 2).

The ASR per 100000 population was highest in Bahrain (46.4) followed by Kuwait (44.3), Qatar (35.5), UAE (19.2), Oman (14.4) and Saudi Arabia (12.9).

For analysis in this paper, Bahrain, Kuwait and Qatar were classified as "high-incidence countries" and UAE, Saudi Arabia and Oman as "low-incidence countries".

\section{Reproductive history of women}

Figure 1 depicts the total fertility rate in the GCC countries during the late 1970s and 1980s as well as the mid 1990s. It can be observed that over the years the number of births per woman consistently decreased in every GCC country. More interestingly, the fertility rate in the low-incidence countries was greater than in the high-incidence countries.

The FHS results indicated that 3\%-12\% of women aged 40-44 years had their first child before age 15 years, whereas this figure was only around $2 \%$ for women currently aged 15-19 years (Figure 2). Similarly, the proportion of women who had their first child between 15 and 19 years of age ranged from $32 \%$ to $42 \%$ among women aged 40-44 years and (except in the UAE) less than $9 \%$ among women currently aged 15-19 years (Figure 3).

The duration of breastfeeding in $\mathrm{Ku}$ wait and Qatar was consistently lower than other countries and there was a decline in duration of breastfeeding among younger women (15-19 years) compared with older women (45-49 years) in all the GCC countries except in Qatar, where data were not available (Figure 4).

\begin{tabular}{|c|c|c|c|c|c|c|c|}
\hline \multirow[t]{2}{*}{ Country } & \multicolumn{4}{|c|}{ Total female: } & \multirow{2}{*}{$\begin{array}{c}\text { CIR } \\
\text { per } \\
100000\end{array}$} & \multirow{2}{*}{$\begin{array}{c}\text { ASR } \\
\text { per } \\
100000\end{array}$} & \multirow{2}{*}{$\begin{array}{c}\text { Age at diagnosis } \\
\text { (years) } \\
\text { Mean (SD) }\end{array}$} \\
\hline & $\begin{array}{c}\text { Population } \\
\text { No. }\end{array}$ & $\begin{array}{c}\text { Cancers } \\
\text { No. }\end{array}$ & $\begin{array}{c}\text { Breas } \\
\text { No. }\end{array}$ & $\begin{array}{c}\text { cancer } \\
\%\end{array}$ & & & \\
\hline UAE & 385392 & 787 & 182 & 23.1 & 9.4 & 19.2 & $47.5(11.8)$ \\
\hline Saudi Arabia & 7418119 & 14694 & 2987 & 20.3 & 8.1 & 12.9 & $48.3(13.5)$ \\
\hline Oman & 874357 & 2070 & 333 & 16.1 & 7.6 & 14.4 & $48.0(13.5)$ \\
\hline Bahrain & 197318 & 951 & 337 & 35.4 & 34.2 & 46.4 & $49.0(12.5)$ \\
\hline Qatar & 88601 & 383 & 90 & 23.5 & 20.3 & 35.5 & $46.7(12.8)$ \\
\hline Kuwait & 418212 & 1662 & 551 & 33.2 & 26.4 & 44.3 & $50.4(12.4)$ \\
\hline
\end{tabular}

Source: Five-year cancer incidence report for the GCC countries published in 2006 [10].

$U A E=$ United Arab Emirates; $S D$ = standard deviation 


\begin{tabular}{|c|c|c|c|c|c|c|}
\hline \multirow{2}{*}{$\begin{array}{l}\text { Age group } \\
\text { (years) }\end{array}$} & \multicolumn{6}{|c|}{ ASR (per 100000 population) } \\
\hline & UAE & $\begin{array}{l}\text { Saudi } \\
\text { Arabia }\end{array}$ & Oman & Bahrain & Qatar & Kuwait \\
\hline $15-19$ & - & $<0.05$ & 0.3 & - & - & - \\
\hline 20-24 & 1.0 & 0.7 & 0.8 & 3.3 & - & - \\
\hline 25-29 & 3.7 & 4.1 & 5.2 & 2.7 & 8.0 & 9.7 \\
\hline 30-34 & 14.2 & 11.7 & 7.2 & 29.1 & 26.6 & 24.1 \\
\hline $35-39$ & 27.1 & 22.4 & 22.1 & 68.7 & 54.9 & 35.5 \\
\hline 40-44 & 53.0 & 30.5 & 29.7 & 114.2 & 64.0 & 73.9 \\
\hline $45-49$ & 37.6 & 32.4 & 43.7 & 120.6 & 106.4 & 151.7 \\
\hline $50-54$ & 80.4 & 31.5 & 52.7 & 163.3 & 64.5 & 123.2 \\
\hline $55-59$ & 54.2 & 32.9 & 32.5 & 116.3 & 76.4 & 136.9 \\
\hline $60-64$ & 49.7 & 38.7 & 41.8 & 97.6 & 75.3 & 109.9 \\
\hline 65-69 & 26.6 & 39.6 & 21.6 & 182.6 & 156.4 & 210.5 \\
\hline $70-74$ & 65.4 & 28.5 & 45.1 & 100.2 & 149.3 & 68.6 \\
\hline $75+$ & 29.8 & 26.5 & 22.9 & 89.4 & 140.4 & 134.4 \\
\hline
\end{tabular}

Source: Five-year cancer incidence report for the GCC countries [10]. $U A E=$ United Arab Emirates.

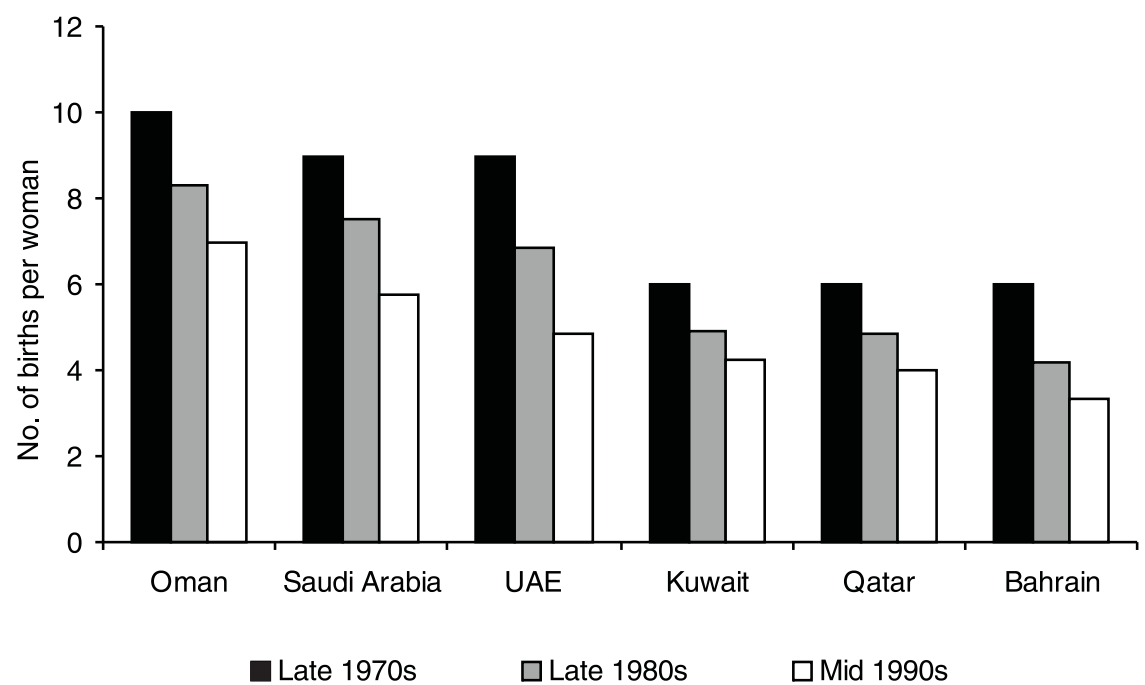

Figure 1 Time trends in total fertility rate in women of Gulf Cooperation Council countries from the late-1970s to the mid-1990s. Source: Family health survey in each GCC country in 1996 [11-16], and child health survey in each GCC country during 1987-89 [22-27]

المجلة الصحية لشرق المتو سط، منظمة الصحة العالمية، المجلد الخامس عشر، العدد ب، 9 +. 


\section{Discussion}

Knowledge of the descriptive epidemiology of breast cancer is useful both in suggesting etiologic hypotheses and, if preventive measures can be identified, in delineating high-risk groups to be targeted for preventive efforts [17]. The most notable characteristic of the descriptive epidemiology of breast cancer in recent years is perhaps the rapidly increasing incidence rates in developing countries that, until recently, had low rates of the disease. In GCC countries breast cancer is the most common malignancy among women of GCC nationality.

The ASR of Bahrain, Kuwait and Qatar was higher than Japan and closer to some European countries $[2,10]$. However, the rate was much lower than in Australia, New Zealand and the United States of America [2]. The rate for UAE, Saudi Arabia and Oman (low-incidence GCC countries) was almost half that in other GCC countries (high-incidence GCC countries). These differences between regions are partly explained by changes in the age distribution of the population and partly due to a real increase in risk, although the GCC population is fairly homogeneous with respect to cultural, environmental and lifestyle, especially food, habits. The population aged over 24 years in the high-incidence GCC countries ranged from $39 \%$ to $44 \%$ in contrast to the low-incidence area $(31 \%-37 \%)$.

The age-specific breast cancer rates in GCC countries were different from those observed in a Korean study [18]: a linear increase with age in the industrialized countries and an inverted V-shaped curve. The incidence started to increase among women in their mid-20s and steeply increased for women in their late-40s. Then there was a slow increase during the rest of their lives. Only 4 breast cancer patients in our study were younger than 20 years; $4.5 \%$ were in
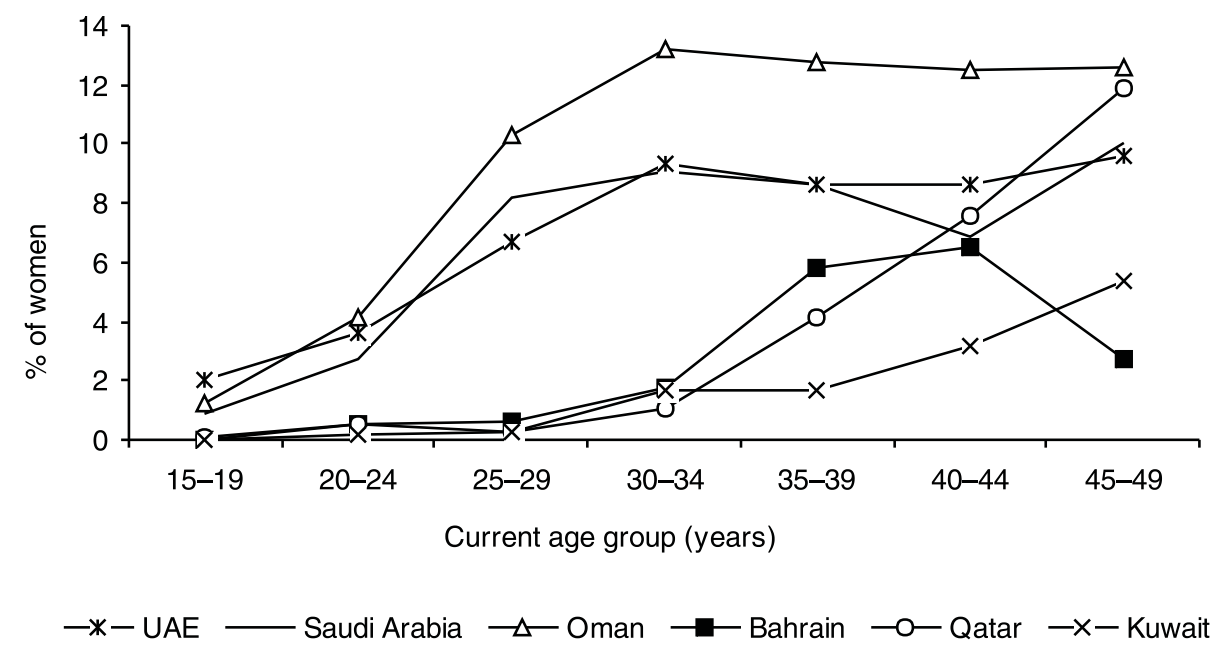

Figure 2 Distribution of women in Gulf Cooperation Council countries who first gave birth before 15 years of age according to current age. Source: Family health survey in each GCC country in 1996 [11-16]

المجلة الصحية لشرق المتوسط، منظمة الصحة العالمية، المجلد الخنامس عشر، العدد ب، 9 +. 


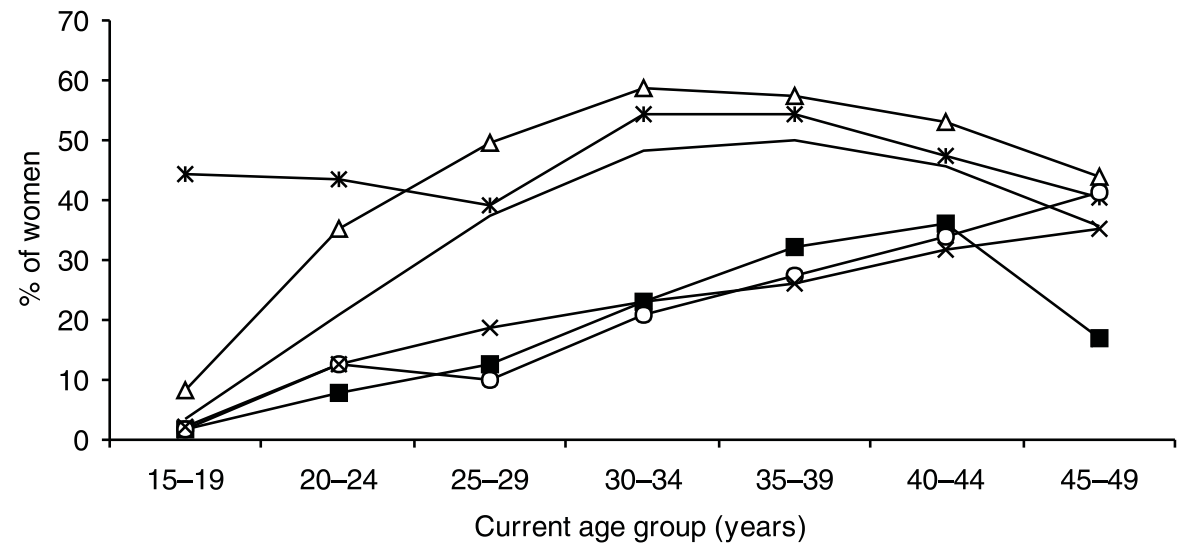

* UAE - Saudi Arabia $\neg-$ Oman $\rightarrow-$ Bahrain $\multimap-$ Qatar $\multimap$ Kuwait

Figure 3 Percentage distribution of women in Gulf Cooperation Council countries who first gave birth between 15 and 19 years of age according to current age. Source: Family health survey in each GCC country in 1996 [11-16]

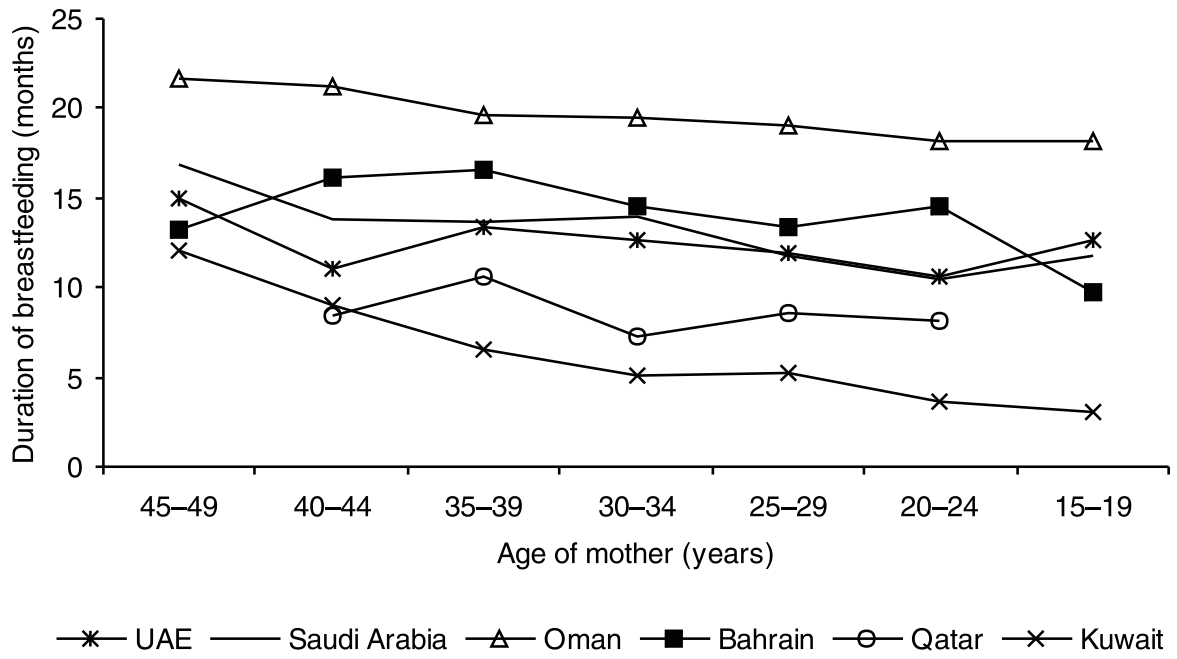

Figure 4 Mean duration of breastfeeding by women in Gulf Cooperation Council countries according to mother's age. Source: Family health survey in each Gulf Cooperation Council country in 1996 [11-16]

المجلة الصحية لشرق المتو سط، منظمة الصحة العالمية، المجلد الخامس عشر، العدد ب، 9 +. 
their $20 \mathrm{~s}$, and $21.6 \%, 32.0 \%, 20.8 \%$ and $21.0 \%$ were in their $30 \mathrm{~s}, 40 \mathrm{~s}$ and $50 \mathrm{~s}$ and $60+$ years of age respectively.

Geographical variations, time trends and studies on populations migrating from low- to high-risk areas show that the incidence in such populations approaches that of the host country within 1 or 2 generations, clearly suggesting an important role of environmental factors in the etiology of breast cancer [19]. On the other hand, there are large differences in the incidence between populations, which support hypotheses about lifestyle, such as use of oral contraceptives, breastfeeding habits, menstrual cycle characteristics, physical activity and dietary habits, as risk factors for breast cancer. Demographic risk factors, including high socioeconomic status, having never married and urban residence, also support the hypothesis about lifestyle.

Most of the well known risk factors for breast cancer are related to the reproductive life of women: early menarche, nulliparity or number of children, late age at first birth, shorter duration of breastfeeding and late menopause. The role of these factors with respect to GCC nationality women is unknown, as studies on breast cancer risk factors in these countries are lacking. The traditional reproductive pattern observed in GCC countries is characterized by an early start to childbearing, short birth intervals (lengthened primarily by prolonged breastfeeding) and an ultimately high parity.

Nulliparity has been identified as a risk factor for breast cancer and increasing parity has been inversely associated with the risk of breast cancer [20]. Among parous women, an increased number of full-term pregnancies has been associated with a statistically significant decrease in the risk of breast cancer, reducing by $14 \%$ for each additional birth [21]. In GCC countries, comparison of FHS results with those from the child health survey [22-27] and earlier studies confirm that the fertility rate in lowincidence areas was consistently higher than high-incidence areas over time and there has been a considerable decline in fertility levels in all the GCC countries.

The risk of breast cancer in women who had their first child after the age of 30 years has been shown to be about twice that of women who had their first child before the age of 20 years [28]. The highest risk group was those who had a first child after the age of 35 years; these women appeared to be at even higher risk than nulliparous women [28]. In GCC countries, the FHS results indicate that there has been a steady rise in the age at first birth over time. While 3\%-12\% of women aged 40-44 years had their first child before age 15 years, only around $2 \%$ of women currently aged 15-19 years did so. Similarly, the percentage of women who had their first child between 15 and 19 years of age was $32 \%-42 \%$ among women aged 40-44 years and $<9 \%$ among women currently aged 15-19 years (except in the UAE where it was $44.2 \%$ ). Furthermore, the decline in early childbearing was more rapid in the high-incidence areas for breast cancer than in the low-incidence areas; the high-incidence areas started on the path of late childbearing 2 decades before the low-incidence areas and reached the level of no childbirth before age 15 years among women aged 15-19 years (Kuwait and Bahrain $0 \%$ and Qatar $0.1 \%$ ).

Marriage and fertility are interrelated and sequential phases in the lifecycles of GCC nationality women. In these countries, age at marriage is a primary indicator of women's exposure to the risk of pregnancy and therefore of first birth. Comparing FHS results with earlier studies shows an upward trend in age at first marriage among GCC women during the period 1995-98 compared to 1987-89 [11-15,22-27]. Therefore 
the age at first birth is also increasing, which is a risk factor for breast cancer.

According to a 2002 collaborative study, a woman's risk for breast cancer decreased by about $4.3 \%$ for every 12 months she breastfed and the risk went down 7\% more for every child born [29]. The FHS results in GCC countries indicate that the duration of breastfeeding in Kuwait and Qatar was consistently lower than other countries and there has been a decline in the duration of breastfeeding in the younger cohort than the older cohort in all GCC countries.

Cultural practices, rapidly increasing socioeconomic status and availability of good medical infrastructure are common to the GCC region, in addition to a similar geographic location. Similar changes in lifestyle, especially a declining fertility rate and duration of breastfeeding, have been taking place in all these countries over the period of the study but these declines were earlier in Bahrain, Qatar and Kuwait than in the other countries. Moreover, changes in dietary patterns (towards high-fat consumption), increased obesity and increased smoking are similar in all these countries [author's personal observation]. It is also likely that younger women are benefitting from improved health care and may be more willing to adhere to recommended interventions than older women. The impact of all these factors on the disparities in breast cancer incidence is unknown, as to the best of our knowledge there are no published studies. Previous studies on the descriptive epidemiology of breast cancer from this region were hospital-based [3-9], reflecting referral patterns and inherent selection bias associated with different hospitals rather than the true incidence, and thus preclude any meaningful comparisons of breast cancer incidence within and outside GCC countries.
However, the present study, which is based on population data that are rarely available from this region, has an advantage over the previous studies. Our results provide a comprehensive description of the epidemiology of breast cancer in the GCC region with valid comparisons among countries, and the opportunity to generate clues to the etiology of breast cancer. One weakness of our study is the unknown effect on breast cancer rates of public health interventions such as the stepwise expansion of breast cancer screening programmes for Emirati women (started in 1996), opportunistic breast examinations for Bahraini and Qatari women (started in late 1990) and educational programmes in Oman and Kuwait.

Nevertheless, we found that breast cancer was the leading cancer among GCC nationality women in all GCC countries. The incidence is low compared with industrialized countries in Europe and North America, perhaps due to the higher rates of multiparity, higher fertility rates, earlier childbirth and longer duration of breastfeeding by women in GCC countries. The differences in incidence rates among GCC countries reflect the history of reproductive factors of each country. In all countries in this study, the increase in age-specific incidence after age 50 years is substantially different from that seen in industrialized countries, where the incidence continues to increase with increasing age $[2,10]$. When women who are currently premenopausal reach the postmenopausal years, however, they will show a greater increase in breast cancer than now due to the cohort effect. Thus we expect an increase in breast cancer incidence in the future, mainly in women above 50 years old. Moreover, the public awareness, educational programmes and screening programmes started in all these

المجلة الصحية لشرق المتو سط، منظمة الصحة العالمية، المجلد الخامس عشر، العدد ب، 9 +. 
countries (except Saudi Arabia), together with rapidly increasing socioeconomic status, higher life expectancy and availability of good medical infrastructure, will contribute to increases in reported incidence.

With substantial changes occurring in the established risk factors, breast cancer in GCC countries is a growing health problem, suggesting the need for further investigations to disentangle inter-related risk factors and to assist in designing interventions.

The relationship between pregnancy and breast cancer is particularly intriguing, because the incidence of breast cancer during pregnancy is significantly lower but also due to the so-called dual effect of pregnancy on risk. Although a protective effect of pregnancy is known, this is not true for the first year after birth, and the protection provided by pregnancy is also mitigated by the age of the mother at birth [30].

There is probably much more that can be learned about the role of hormones from studies on the effect of pregnancy on breast cancer. Future epidemiological studies on breast cancer in GCC countries should focus on reproductive factors. This is of particular interest because the classic excess of nulliparous women among breast cancer cases is not seen among the population described here. Such a study would provide new insights into the etiology of breast cancer and assist in planning health interventions for early detection.

\section{References}

1. Ferlay J et al. Cancer incidence, mortality and prevalence worldwide, 2nd ed. Lyon, International Agency for Research on Cancer, 2004.

2. Parkin DM et al. Cancer incidence in five continents. Lyon, International Agency for Research on Cancer, 2002.

3. Mansoor I. Profile of female breast lesions in Saudi Arabia. Journal of the Pakistan Medical Association, 2001, 51(7):243-7.

4. Ibrahim EM et al. Breast cancer in the eastern province of Saudi Arabia. Medical oncology, 1998, 15(4):241-7.

5. Fakhro AE et al. Breast cancer: patient characteristics and survival analysis at Salmaniya medical complex, Bahrain. Eastern Mediterranean health journal, 1999, 5(3):430-9.

6. Ezzat AA et al. Locally advanced breast cancer in Saudi Arabia: high frequency of stage III in a young population. Medical oncology, 1999, 16(2):95-103.

7. Anim JT et al. Breast cancer as seen in King Fahd University Hospital, Al-Khobar,
1983-1986. Journal of the Royal College of Surgeons of Edinburgh, 1989, 34(4):201-4.

8. Al-Idrissi $\mathrm{HY}$ et al. Breast cancer in a low-risk population. The influence of age and menstrual status on disease pattern and survival in Saudi Arabia. International journal of cancer, 1992, 52(1):48-51.

9. Al-Idrissi HY. Pattern of breast cancer in Saudi females in eastern province of Saudi Arabia. Indian journal of medical sciences, 1991, 45(4):85-7.

10. Al-Zahrani AS, Ravichandran K, Al-Madouj AN. Five year cancer incidence report for the Gulf Cooperation Council Countries, 1998-2002. Riyadh, Gulf Centre for Cancer Registration, 2006.

11. Alnesef $\mathrm{Y}, \mathrm{Al}$-Rashoud R, Farid S. Kuwait family health survey 1996. Kuwait, Ministry of Health, 2000.

12. Fikri M, Farid S. United Arab Emirates family health survey 1996. Abu Dhabi, United Arab Emirates, Ministry of Health, 2000. 
13. Jaber KA, Farid S. Qatar family health survey 1996. Doha, Ministry of Health, 2000

14. Khoja TA, Farid S. Saudi Arabia family health survey 1996: principal report. Riyadh, Ministry of Health, 2000.

15. Naseeb T, Farid S. Bahrain family health survey 1996. Manama, Ministry of Health, 2000.

16. Suleiman MJ, Al-Riyami A, Farid S. Oman family health survey 1996. Muscat, Ministry of Health, 2000.

17. Kelsey JL, Horn-Ross PL. Breast cancer: magnitude of the problem and descriptive epidemiology. Epidemiologic reviews, 1993, 15(1):7-16.

18. Yoo KY et al. Epidemiology of breast cancer in Korea: occurrence, high-risk groups, and prevention. Journal of Korean medical science, 2002, 17(1):1-6.

19. Pisani P. Breast cancer: geographic variation and risk factors. Journal of environmental pathology, toxicology and oncology, 1992, 11(5-6):313-6.

20. Kelsey JL, Gammon MD, John EM. Reproductive factors and breast cancer. Epidemiologic reviews, 1993, 15(1):36-47.

21. Andrieu $\mathrm{N}$ et al. Pregnancies, breastfeeding, and breast cancer risk in the International BRCA1/2 Carrier Cohort Study (IBCCS). Journal of the National Cancer Institute, 2006, 98(8):535-44.

22. Al Mazrou Y, Farid S. Saudi Arabia child health survey 1987. Riyadh, Ministry of Health, 1991.
23. Al Muhaideb A, Abdul Ghafour A, Farid S. United Arab Emirates child health survey 1987. Abu Dhabi, United Arab Emirates, Ministry of Health, 1991.

24. Al-Rashoud R, Farid S. Kuwait child health survey 1987. Kuwait, Ministry of Health, 1991.

25. Salman A, Al Jaber K, Farid S. Qatar child health survey 1987. Doha, Ministry of Health, 1991.

26. Yacoub I, Farid S. Bahrain child health survey 1989. Manama, Ministry of Health, 1991.

27. Suleiman MJ, Al Ghassany A, Farid S. Oman child health survey 1988-89. Muscat, Ministry of Health, 1992.

28. McPherson K, Steel CM, Dixon JM. ABC of breast diseases. Breast cancer-epidemiology, risk factors, and genetics. British medical journal, 2000, 321(7261):624-8.

29. Collaborative Group on Hormonal Factors in Breast Cancer. Breast cancer and breastfeeding: collaborative reanalysis of individual data from 47 epidemiological studies in 30 countries, including 50302 women with breast cancer and 96973 women without the disease. Lancet, 2002 360(9328):187-95.

30. Albrektsen G, Heuch I, Kvåle G. The short-term and long-term effect of a pregnancy on breast cancer risk: a prospective study of 802457 parous Norwegian women. British journal of cancer, 1995, 72(2):480-4. 